\title{
FAKTOR YANG MEMPENGARUHI CUSTOMER LOYALTY DI CARREFOUR
}

\author{
Warniancy Ariesty \\ Fakultas Manajemen \& Bisnis, Universitas Ciputra Surabaya \\ warniancyariesty@gmail.com
}

\begin{abstract}
ABSTRAK
Persaingan bisnis retail yang semakin meningkat menuntut para pebisnis untuk menciptakan keunggulan kompetitif agar dapat mempertahankan pangsa pasarnya. Salah satu bisnis retail yang sedang marak di Indonesia yaitu Carrefour. Carrefour memiliki pelanggan yang sangat loyal dibandingkan dengan hypermarket yang lain. Namun, Carrefour tentu harus mempertahankan atau meningkatkan performance agar dapat mewujudkan customer loyalty. Customer satisfaction berkaitan dengan customer loyalty. Untuk meningkatkan customer satisfaction, Carrefour berupaya untuk dapat meningkatkan service quality. Tujuan penelitian yaitu untuk menguji dan menganalisis faktor-faktor yang mempengaruhi service quality terhadap customer satisfaction yang berdampak pada customer loyalty dalam memilih hypermarket. Objek penelitian yaitu pelanggan Carrefour kota besar di Indonesia. Metode penelitian yang digunakan adalah dengan metode penelitian kuantitatif dengan teknik pengambilan sampel data dilakukan dengan menggunakan accidental sampling yang termasuk dalam nonprobability sampling. Data jawaban responden yang merupakan hasil dari penyebaran kuesioner kepada pelanggan Carrefour, diolah dan dianalisis menggunakan metode analisis data yaitu SEM (Structural Equation Modeling) berbasis PLS (Partial Least Square). Hasil penelitian yang diperoleh yaitu variabel service quality berpengaruh terhadap customer satisfaction dan customer loyalty.
\end{abstract}

Kata kunci: Service Quality, Satisfaction, Loyalty

\section{PENDAHULUAN}

Industri retail merupakan bidang usaha yang sedang berkembang di masyarakat Indonesia sehingga membutuhkan kemampuan untuk dapat bersaing dengan sesama industri retail baik lokal maupun asing. Menurut Asosiasi Perusahaan Ritel Indonesia (Aprindo), pertumbuhan bisnis retail sejalan dengan perbaikan perekonomian Indonesia pada tahun 2016 yang berdampak pada daya beli masyarakat yang semakin meningkat. Kehadiran industri retail pada dasarnya memanfaatkan pola belanja masyarakat di kawasan perkotaan dimana lebih memilih berbelanja di pusat perbelanjaan modern dibandingkan berdesak-desakan di dalam pasar tradisional yang kebanyakan tidak tertata rapi. Hal ini tentu semakin memacu para pemain dalam bisnis retail untuk membenahi segala aspek agar dapat terus mengembangkan bisnisnya.

Sebagaimana struktur dinamis dan persaingan yang ketat di pasar retail yang makin meningkat, maka para pengecer supermarket menggunakan strategi terfokus untuk mendapatkan pelanggan yang setia (Okumus dan Temizler, 2006). Setiap industri retail tentu membutuhkan strategi untuk menjaga kualitas produk atau layanan dalam memenuhi permintaan konsumen yang beragam untuk menjaga loyalitas konsumen. Hal tersebut merupakan masalah penting yang dihadapi oleh manajemen bisnis retail saat ini. Bisnis retail tidak sesederhana menampilkan barang di toko untuk memenuhi kebutuhan konsumen.

Carrefour merupakan hypermarket yang berasal dari Perancis yang bergerak dalam bidang dagang. Dengan adanya persaingan yang semakin marak, banyak faktor-faktor yang dapat memicu pelanggan untuk berpindah dari satu toko retail ke toko retail yang lain. Saat ini Carrefour telah memiliki 89 outlet yang tersebar di seluruh Indonesia. Seiring dengan pertumbuhan ekonomi di beberapa kota, Carrefour terus berupaya untuk menambah outletnya.

Pada era globalisasi, banyak perusahaan retail yang memahami bahwa customer loyalty merupakan hal yang tidak terelakkan lagi bagi perusahaan, tidak terkecuali Carrefour. Carrefour 
terus berupaya untuk memberikan service quality yang terbaik bagi konsumennya karena memiliki efek yang sangat besar bagi kelangsungan perusahaan agar bisa tetap eksis dan mampu mempertahankan pangsa pasar. Asosiasi Perusahaan Ritel Indonesia (Aprindo) menambahkan bahwa pertumbuhan bisnis retail di Indonesia antara $10 \%-15 \%$ per tahun dimana jumlah pendapatan terbesar merupakan kontribusi dari hypermarket, kemudian disusul oleh supermarket dan minimarket.

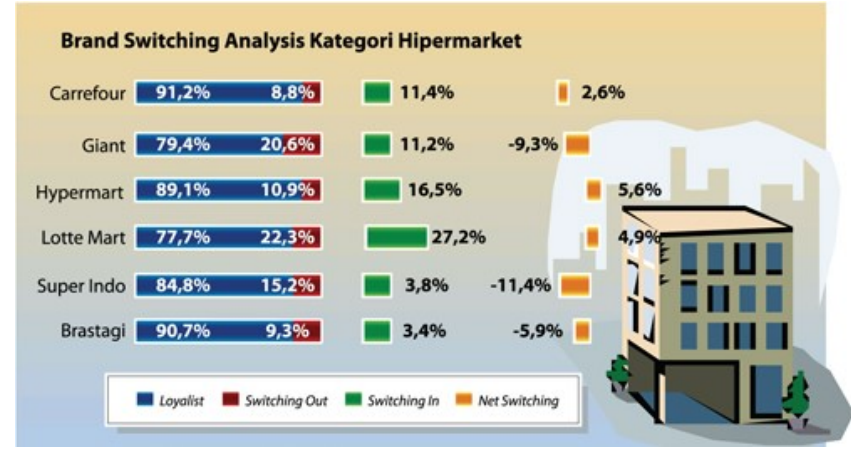

Gambar 1: Brand Switching Analysis Kategori Hypermarket (Frontier Consulting Group, 2012)

Gambar 1 menunjukkan bahwa berdasarkan brand switching analysis di atas, dapat terlihat bahwa Carrefour termasuk salah satu merek yang diprediksikan akan bertambah jumlah pengunjungnya di masa mendatang yang ditunjukkan dengan angka net switching positif.

Angka switching in menunjukkan bahwa jumlah pengunjung merek lain yang akan berganti mengunjungi Carrefour sebanyak $11.4 \%$ sedangkan pengunjung Carrefour yang akan berpindah menggunakan merek lain (switching out) sebanyak 8.8\%. Walaupun Carrefour memiliki angka loyalist paling tinggi yaitu $91.2 \%$ dibandingkan dengan merek yang lain, Carrefour tetap harus mempertahankan atau meningkatkan performance mereka sehingga angka switching out semakin dapat diminimalisir.

Dalam sektor retail, pelayanan yang berkualitas, memuaskan konsumen dan memiliki pelanggan yang setia selama bertahun-tahun merupakan hal yang penting. Menciptakan kepuasan dan loyalitas konsumen dapat memberikan keunggulan kompetitif dan diferensiasi dari pesaing. Kualitas dan kepuasan konsumen yang berorientasi pada layanan, harus diteliti lebih lanjut untuk memahami dinamika loyalitas konsumen (Hutchinson et al., 2009).

Berdasarkan permasalahan tersebut, maka dapat diambil beberapa rumusan masalah sebagai berikut:

1. Apakah Service Quality berpengaruh positif terhadap Customer Satisfaction?

2. Apakah Customer Satisfaction berpengaruh positif terhadap Customer Loyalty?

3. Apakah Service Quality berpengaruh terhadap positif Customer Loyalty?

\section{LITERATURE REVIEW}

\section{Hubungan Service Quality dengan Customer Satisfaction}

Ada banyak faktor yang menciptakan customer satisfaction dan customer loyalty dalam literatur, salah satu faktor tersebut adalah service quality (Kursunluoglu, 2014). Service quality didefinisikan sebagai penilaian seberapa baik layanan disampaikan sesuai dengan harapan pelanggan (Shin, 2014). Salah satu cara untuk membedakan layanan suatu perusahaan dari para pesaingnya adalah dengan menawarkan layanan yang berkualitas tinggi (Dadfar dan Brege, 
2012; Miles, 2013). Parasuraman et al (1988) mengatakan bahwa "service quality terdiri dari lima dimensi yaitu tangibles, reliability, responsiveness, assurance, empathy”.

Oleh karena itu, sebagai pengembangan, service quality telah diidentifikasikan sebagai strategi kunci untuk meningkatkan customer satisfaction dan keinginan untuk mengunjungi kembali, memberikan layanan berkualitas bagi pelanggan sangat penting untuk menimbulkan retensi dan customer satisfaction (Lee et al., 2011).

Penelitian sebelumnya telah menetapkan bahwa hubungan antara service quality dan customer satisfaction umumnya positif (Liang dan Zhang, 2009). Ditemukan bahwa pelanggan yang puas lebih mungkin untuk menunjukkan kesetiaan kepada penyedia layanan dengan membeli kembali, atau merekomendasikan layanan kepada orang lain (Senic dan Marinkovic 2014).

Berdasarkan penjelasan yang dipaparkan, maka hipotesis dirumuskan sebagai berikut:

H1: Service Quality berpengaruh positif terhadap Customer Satisfaction

\section{Hubungan Customer Satisfaction dengan Customer Loyalty}

Pertumbuhan industri retail yang pesat memaksa para pemain untuk terus berkompetisi dalam menerapkan strategi bersaingnya, salah satunya yaitu melalui customer satisfaction. Memuaskan konsumen adalah tantangan bisnis di pasar yang kompetitif saat ini. Perusahaan telah menyadari betapa pentingnya memahami, memenuhi dan memprediksi kebutuhan konsumennya. Kotler (2000) mengatakan bahwa "kepuasan adalah perasaan senang atau kecewa seseorang yang dihasilkan dari membandingkan kinerja atau hasil suatu produk yang dirasakan dalam kaitannya dengan harapan-harapannya".

Customer satisfaction sejak lama diajukan sebagai salah satu indikator non-keuangan yang paling penting dari kesuksesan bisnis secara keseluruhan dan keberlanjutan (Suriyankietkaew, 2016). Customer satisfaction yang tinggi membawa banyak manfaat yang mendukung kelangsungan perusahaan, termasuk profitabilitas yang berkelanjutan, meningkatkan retensi jangka panjang dan loyalitas konsumen, serta meningkatkan reputasi perusahaan (Ahearne et al, 2005; Hallowell, 1995; Ittner dan Larcker, 2003). Perusahaan yang dapat memenuhi kebutuhan dan harapan konsumen, maka dipandang sebagai perusahaan yang mampu memberikan kepuasan kepada konsumennya. Oleh karena itu, layanan yang ditawarkan oleh setiap perusahaan harus memberikan nilai yang sesuai dengan apa yang dinginkan oleh konsumen.

Lam \& Burton (2006) menegaskan bahwa customer satisfaction sering menjadi penentu utama customer loyalty. Ehigie (2006) menyatakan bahwa "terdapat hubungan yang positif dan signifikan antara customer satisfaction dengan customer loyalty". Hal tersebut diperkuat dengan gagasan yang dikemukakan oleh Verhoef (2003) dimana menunjukkan bahwa customer satisfaction memiliki dampak positif yang signifikan pada customer loyalty. Literatur akademik mengatakan bahwa jika pelanggan puas dengan merek yang mereka pilih, maka mereka akan cenderung untuk kembali membeli produk atau jasa tersebut dan akhirnya menjadi pelanggan yang setia.

Konsumen yang puas dapat menjadi sumber yang baik untuk meningkatkan profitabilitas. Hal tersebut disebabkan oleh konsumen yang puas cenderung berkomitmen untuk memiliki interaksi sosial yang lebih baik dengan penyedia layanan, sementara konsumen yang tidak puas akan mengeluh dan tidak akan melakukan pembelian kembali (Lee et al., 2011).

Berdasarkan penjelasan yang dipaparkan, maka hipotesis dirumuskan sebagai berikut:

H2: Customer Satisfaction berpengaruh positif terhadap Customer Loyalty 


\section{Hubungan Service Quality dengan Customer Loyalty}

Wulf, Schored \& Lacobucci (2001) mendefinisikan customer loyalty sebagai besarnya frekuensi konsumsi dan pembelian dari konsumen terhadap produk atau jasa dari sebuah perusahaan. Sedangkan menurut Sheth \& amp; Mittal (2004), “customer loyalty adalah komitmen konsumen berdasarkan sikap yang positif dimana tercermin dalam pembelian berulang yang konsisten". Hal ini didukung oleh Kotler \& Keller (2007), dimana indikator customer loyalty adalah repurchase (loyalitas terhadap pembelian produk); retention (ketahanan terhadap pengaruh negatif dari perusahaan); referalls (memberikan referensi kepada orang lain sehubungan dengan produk dan jasa).

Konsumen dapat menjadi loyal terhadap suatu produk atau jasa yang ditawarkan oleh sebuah perusahaan dikarenakan merasa puas dan berkeinginan untuk melanjutkan hubungannya dengan perusahaan. "Konsumen yang setia sangat penting untuk perusahaan karena biaya untuk mempertahankan pelanggan yang sudah ada lebih sedikit daripada menarik pelanggan baru" (Anderson dan Mittal, 2000). Dengan kata lain, pelanggan yang loyal merupakan sumber pendapatan perusahaan yang konsisten melalui pembelian ulang dan sekaligus menurunkan biaya dengan berkurangnya biaya promosi, sehingga dapat meningkatkan keuntungan.

Berdasarkan penjelasan yang dipaparkan, maka hipotesis dirumuskan sebagai berikut:

H3: Service Quality berpengaruh positif terhadap Customer Loyalty

Berdasarkan latar belakang, rumusan masalah, dan hipotesis yang telah dipaparkan, maka kerangka penelitian yang diajukan oleh peneliti adalah sebagai berikut:

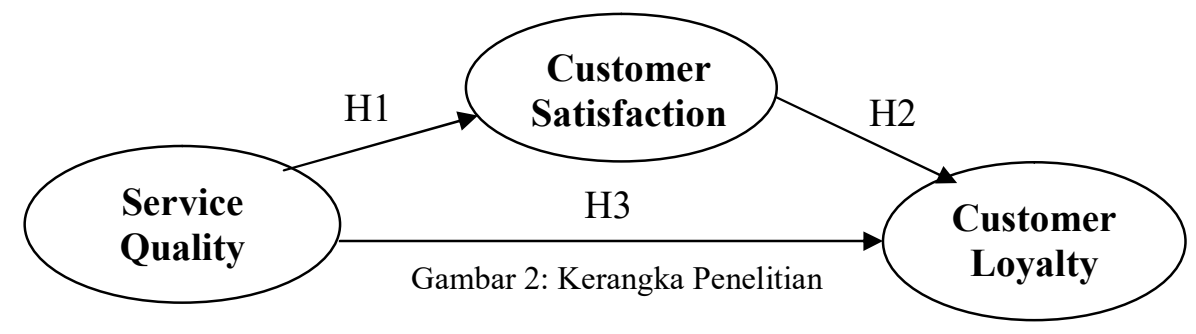

\section{METODE PENELITIAN}

Penelitian ini menggunakan metode penelitian kuantitatif. Sedangkan jenis penelitian yang digunakan adalah explanatory research yaitu penelitian yang dirancang dengan tujuan menguji suatu teori atau hipotesis untuk memperkuat atau bahkan menolak teori atau hipotesis hasil penelitian terdahulu. Teknik pengumpulan data yaitu dengan menggunakan kuesioner dimana penyebarannya dengan menggunakan google forms. Populasi dalam penelitian ini adalah pelanggan Carrefour di Indonesia sedangkan sampelnya yaitu pelanggan Carrefour yang ada di kota-kota besar di Indonesia. Dalam penelitian ini, kota besar di Indonesia dikategorikan berdasarkan jumlah penduduk diatas 100.000 jiwa. Kota-kota tersebut adalah Jakarta, Surabaya, Bandung, Medan, Semarang, Palembang, dan Makassar. Gambar 3 merupakan data yang diperoleh dari www.bps.go.id pada data sensus penduduk 2010 yang menunjukkan jumlah penduduk diatas 100.000 jiwa. 


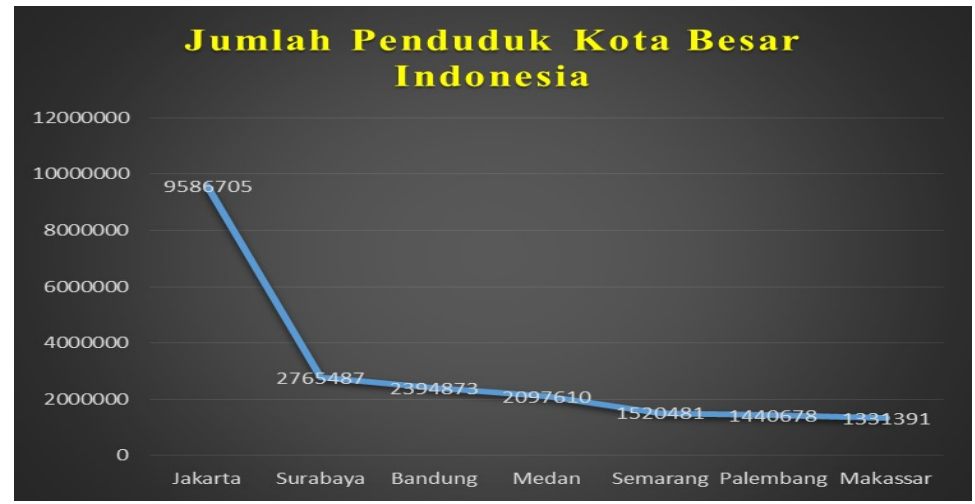

Gambar 3: Jumlah Penduduk Kota Besar Indonesia

(Badan Pusat Statistik, Diolah 2017)

Teknik pengambilan sampel data dilakukan dengan menggunakan accidental sampling yang termasuk dalam nonprobability sampling. Perhitungan jumlah responden dalam penelitian ini menggunakan teori Hair et al. (2013) yaitu sebanyak 110 responden yang diperoleh dari indikator penelitian yang berjumlah 11 dikalikan $10(11 \times 10=110)$.

Pengukuran data pada keseluruhan pernyataan yang terdapat dalam kuesioner yang diajukan kepada responden menggunakan skala likert, yaitu jarak interval 1 sampai dengan 5 dimana angka 1 menunjukkan nilai terendah sedangkan angka 5 menunjukkan nilai tertinggi. Data jawaban responden yang diperoleh dari hasil penyebaran kuesioner kepada pelanggan Carrefour yang ada di kota besar Indonesia yaitu sebanyak 115 dimana 5 jawaban tidak dapat digunakan untuk mengukur variabel dalam penelitian ini. Data tersebut kemudian diolah dan dianalisis menggunakan metode analisis data yaitu SEM (Structural Equation Modeling) berbasis PLS (Partial Least Square).

\section{HASIL DAN PEMBAHASAN}

Dalam penelitian ini, karakteristik responden yang menjadi sampel diklasifikasikan berdasarkan umur, jenis kelamin, pendidikan terakhir, pendapatan per bulan, dan frekuensi belanja di Carrefour dalam 1 bulan. Berikut adalah grafik lingkaran yang menunjukkan karakteristik responden dalam penelitian ini:

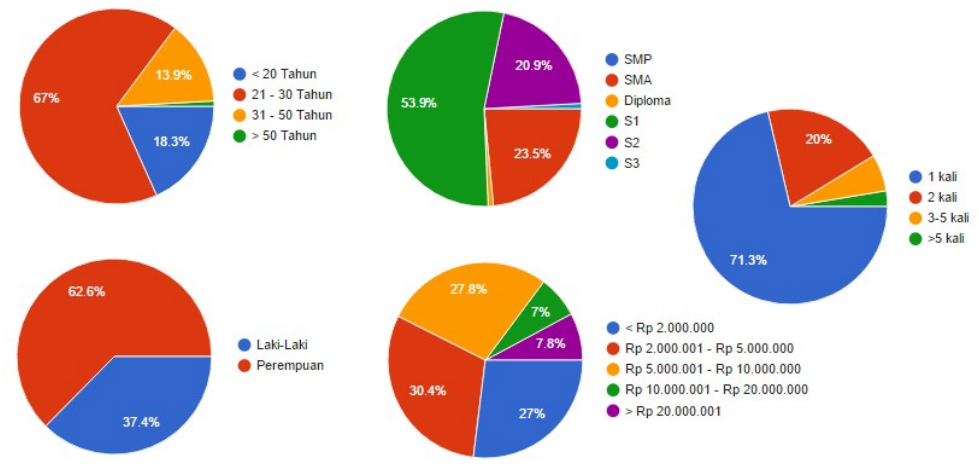

Gambar 4: Grafik Karakteristik Responden

(Pengolahan Data, 2017)

Berdasarkan kuesioner yang diperoleh, Gambar 4 menunjukkan bahwa karakteristik responden lebih banyak didominasi oleh perempuan dengan umur antara 21-30 tahun dimana pendidikan 
terakhirnya yaitu sarjana (S1) dengan pendapatan antara Rp 2.000.001-Rp 5.000.000 per bulan. Adapun frekuensi belanja di Carrefour yaitu paling sedikit 1 kali dalam sebulan.

Dalam penelitian ini, instrumen-instrumen yang digunakan untuk mengukur service quality yaitu keramahan karyawan (tangibles), kemampuan dalam menyediakan layanan yang cepat dan tanggap (reliability), kesediaan untuk membantu pelanggan (responsiveness), keamanan pada saat berbelanja (assurance), dan jam operasional yang terjangkau (empathy). Untuk mengukur variabel customer satisfaction, instrumen-instrumen yang digunakan adalah kepuasan dengan keputusan untuk berbelanja di Carrefour, kepuasan terhadap harga yang diberikan, dan kepuasan terhadap pelayanan yang diberikan. Sedangkan instrumen-instrumen yang digunakan untuk mengukur customer loyalty yaitu pembelian berulang (repurchase), rekomendasi (referalls), dan pilihan pertama untuk berbelanja (retention).

\section{Outer Model}

Hasil analisis dengan menggunakan software smartPLS, menunjukkan hasil pada model pengukuran (measurement model) dan model struktural (structural model). Measurement model atau yang biasa disebut outer model bertujuan untuk menguji validitas dan reliabilitas instrumen dari setiap variabel yang diteliti. Analisis PLS untuk outer model meliputi 3 jenis pengujian yaitu convergent validity, discriminant validity dan composite reliability.

\section{Convergent Validity}

Ghozali (2011) mengatakan bahwa "suatu indikator dikatakan valid jika mempunyai loading factor diatas 0.7 , namun untuk penelitian tahap awal dari pengembangan skala pengukuran nilai loading 0.5 sampai 0.6 dianggap cukup".

Tabel 1. Nilai Loading Factor

\begin{tabular}{ccc}
\hline Indikator & & Nilai \\
\hline \multirow{3}{*}{ Service Quality } & SQ1 & 0.775 \\
\cline { 2 - 3 } & SQ2 & 0.765 \\
\cline { 2 - 3 } & SQ3 & 0.765 \\
\cline { 2 - 3 } & SQ4 & 0.780 \\
\hline \multirow{3}{*}{ Customer Satisfaction } & SQ5 & 0.533 \\
\cline { 2 - 3 } & CS1 & 0.833 \\
\cline { 2 - 3 } & CS3 & 0.830 \\
\hline \multirow{3}{*}{ Customer Loyalty } & CL1 & 0.827 \\
\cline { 2 - 3 } & CL2 & 0.939 \\
\cline { 2 - 3 } & CL3 & 0.813 \\
\hline Sumber: Output & Data PLS $(2017)$
\end{tabular}

Sumber: Output Data PLS (2017)

Berdasarkan hasil yang diperoleh dari pengolahan data, Tabel 1 menunjukkan bahwa semua indikator pada variabel service quality (SQ), terhadap customer loyalty (CL) dimana customer satisfaction (CS) sebagai variabel pemediasi memiliki loading factor yang lebih besar dari 0,5 
menunjukkan bahwa semua indikator dinyatakan valid dalam mewakili setiap variabel yang digunakan.

Jika dianalisa masing-masing variabel, terdapat satu indikator yang memiliki nilai loading factor yang paling tinggi dibandingkan dengan yang lainnya. Untuk variabel service quality, SQ4 (rasa aman pada saat berbelanja di Carrefour) merupakan indikator yang dominan. Untuk variabel customer satisfaction, indikator CS1 (kepuasan dengan keputusan untuk berbelanja di Carrefour) merupakan indikator yang dominan. Sedangkan untuk indikator customer loyalty memiliki CL1 (pembelian berulang di Carrefour) sebagai indikator yang dominan.

\section{Discriminant Validity}

Ghozali (2011) mengatakan bahwa "jika nilai akar kuadrat AVE (average variance extracted) setiap konstruk lebih besar daripada nilai korelasi antara konstruk dengan konstruk lainnya dalam model, maka dikatakan memiliki nilai discriminant validity yang baik, dimana nilai AVE harus lebih besar dari 0.5 ".

\begin{tabular}{cc}
\multicolumn{2}{c}{ Tabel 2. Nilai AVE } \\
\hline & AVE \\
\hline Customer Loyalty & 0.794 \\
\hline Customer Satisfaction & 0.689 \\
\hline Service Quality & 0.532 \\
\hline Sumber: Output Data PLS (2017)
\end{tabular}

Dapat dilihat dari Tabel 2, hasil output PLS menunjukkan nilai AVE $>0.50$. Dengan demikian, maka dapat disimpulkan bahwa model dalam penelitian ini telah memiliki discriminant validity yang baik.

\section{Composite Reliability}

Ghozali (2011) mengatakan bahwa "composite reliability blok indikator yang mengukur suatu konstruk dapat dievaluasi dengan 2 macam ukuran yaitu internal consistency dan cronbach's alpha, dimana nilai composite reliability harus diatas $0.6 "$.

Tabel 3. Nilai Composite Reliability

\begin{tabular}{cc}
\hline & Composite Reliability \\
\hline Customer Loyalty & 0.920 \\
\hline Customer Satisfaction & 0.869 \\
\hline Service Quality & 0.848 \\
\hline Sumber: Output Data PLS (2017)
\end{tabular}

Dari Tabel 3 menunjukkan bahwa hasil output PLS pada nilai composite reliability baik karena nilainya diatas 0.6 . 


\section{Inner Model}

Inner model (structural model) dalam penelitian ini diukur menggunakan nilai koefisien determinasi $\left(\mathrm{R}^{2}\right)$, estimasi koefisien jalur dan nilai t-statistic. Uji ini dilakukan untuk membuktikan hubungan antar variabel laten.

\section{Koefisien determinasi}

Koefisien determinasi dinyatakan dengan $\mathrm{R}^{2} / R$-square dari variabel laten endogenous. Ghozali (2011) menjelaskan bahwa "koefisien determinasi pada intinya mengukur seberapa jauh kemampuan model dalam menerangkan variasi variabel dependen, dimana nilai koefisien determinasi adalah antara nol dan satu".

a. Nilai $\mathrm{R}^{2}$ sebesar 0.67 dikategorikan baik

b. Nilai $\mathrm{R}^{2}$ sebesar 0.33 dikategorikan moderate

c. Nilai $\mathrm{R}^{2}$ sebesar 0.19 dikategorikan lemah

Tabel 4. Nilai Koefisien Determinasi

\begin{tabular}{|c|c|}
\hline & R Square \\
\hline Customer Loyalty & 0.572 \\
\hline Customer Satisfaction & 0.619 \\
\hline
\end{tabular}

Sumber: Output Data PLS (2017)

Dari Tabel 4, nilai R square pada PLS, menunjukkan bahwa nilai koefisien determinasi menyatakan bahwa model dinilai moderate dan mampu menjelaskan variasi variabel dependen.

\section{Koefisien jalur dan T-statistik}

Menurut Ghozali (2011) "nilai - nilai yang diestimasi untuk hubungan jalur dalam model struktural (semua variabel laten) harus dievaluasi dalam perspektif kekuatan dan signifikansi hubungan". Ghozali (2011) menjelaskan bahwa "nilai signifikansi ini dapat diperoleh dengan prosedur bootstrapping dan nilai t-statistic digunakan untuk menyatakan signifikansi konstanta dari setiap variabel independen, apakah benar-benar berpengaruh terhadap variabel dependennya”. Kriteria pengujian menggunakan tingkat signifikansi $(\alpha)=0.05$ dimana apabila $t$ hitung $>\mathrm{t}$ tabel, maka terdapat pengaruh yang signifikan".

Tabel 5. Koefisien Jalur dan Nilai T Statistik

\begin{tabular}{|cccc} 
& $\begin{array}{c}\text { Original Sample } \\
(\mathbf{O})\end{array}$ & $\begin{array}{c}\text { T Statistics } \\
(\mid \mathbf{O} / \text { STERR|) }\end{array}$ & Hasil \\
\hline Customer Satisfaction -> Customer Loyalty & 0.785 & 64.344 & Diterima \\
\hline Service Quality -> Customer Loyalty & 0.581 & 2.466 & Diterima \\
\hline Service Quality -> Customer Satisfaction & 0.787 & 134.224 & Diterima \\
\hline
\end{tabular}

Sumber: Output Data PLS (2017)

Berdasarkan tabel 5, terdapat 3 jalur yang diestimasi hubungan antar variabelnya. Kolom original sample estimate menunjukkan koefisien jalur dari dua variabel yang diukur dan kolom t-statistik menunjukkan hasil perhitungan t-statistik dari jalur yang diukur untuk menyatakan signifikansi hubungan. Besarnya seluruh koefisien jalur pada data diatas bernilai positif (koefisien jalur $>0$ ) yang artinya terdapat pengaruh positif antar kedua variabel tersebut. Bila dilihat pada kolom $\mathrm{t}$-statistik, seluruh nilai t-statistik $>\mathrm{t}$ tabel $(\mathrm{t}$ tabel signifikansi $5 \%$ adalah 
1.96), seluruh nilai t-statistik $>1.96$ artinya terdapat pengaruh yang signifikan antar kedua variabel.

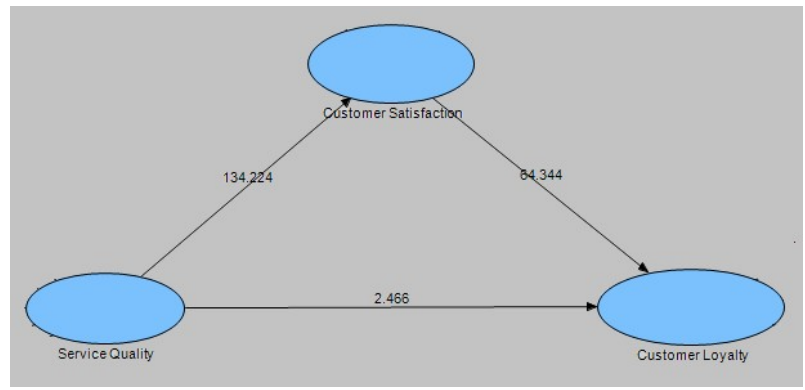

Gambar 5: Tampilan Output Structural Model

(Pengolahan Data, 2017)

Gambar 5 merupakan model hasil penelitian menggunakan software smartPLS yang menunjukkan bahwa ketiga hipotesis yang diajukan dalam penelitian ini diterima, yaitu:

Faktor service quality berpengaruh positif dan signifikan terhadap customer satisfaction. Hal ini membuktikan bahwa Carrefour memberikan pelayanan yang berkualitas kepada konsumennya melalui keramahan karyawan, menyediakan layanan yang cepat dan tanggap, selalu bersedia untuk membantu pelanggan, memberikan keamanan kepada konsumen pada saat berbelanja, dan jam operasional yang terjangkau sehingga dapat memberikan kepuasan kepada setiap konsumen yang berbelanja di Carrefour.

Customer satisfaction berpengaruh positif dan signifikan terhadap customer loyalty. Penelitian ini membuktikan bahwa Carrefour dapat memberikan kepuasan kepada konsumen melalui pelayanan yang sesuai dengan harapan konsumen sehingga konsumen memutuskan untuk memilih Carrefour sebagai tempat untuk berbelanja karena harga yang diberikan sangat terjangkau.

Service quality berpengaruh positif dan signifikan terhadap customer loyalty. Kualitas pelayanan yang disediakan oleh Carrefour dapat membuat konsumen untuk melakukan pembelian berulang sehingga konsumen merekomendasikan Carrefour kepada orang-orang disekitarnya sebagai pilihan pertama untuk berbelanja.

\section{KESIMPULAN}

Berdasarkan hasil pengolahan, analisis data, hasil dan pembahasan yang telah dijelaskan, maka dapat ditarik kesimpulan sebagai berikut :

1. Service Quality berpengaruh terhadap Customer Satisfaction. Semakin tinggi kualitas pelayanan yang diberikan maka semakin tinggi kepuasan konsumen.

2. Customer Satisfaction berpengaruh terhadap Customer Loyalty. Semakin tinggi kepuasan konsumen maka semakin tinggi loyalitas konsumen.

3. Service Quality berpengaruh terhadap Customer Loyalty. Semakin tinggi kualitas pelayanan maka semakin tinggi loyalitas konsumen.

Berdasarkan hasil penelitian, maka peneliti memberikan beberapa saran yang perlu disempurnakan baik oleh praktisi maupun teoritis, yaitu sebagai berikut:

1. Untuk lebih meningkatkan kepuasan konsumen dan loyalitas konsumen, maka pelayanan secara langsung terhadap konsumen Carrefour harus lebih ditingkatkan. 
2. Untuk mengetahui pengaruh kualitas pelayanan terhadap kepuasan konsumen dan loyalitas konsumen pada seluruh Carrefour yang ada di Indonesia, maka peneliti menyarankan pengambilan sampel lebih luas dimana mewakili seluruh outlet Carrefour.

\section{REFERENSI}

Ahearne, M., Mathieu, J. \& Rapp, A. (2005). "To empower or not to empower your sales force? An empirical examination of the influence of leadership empowerment behaviour on customer satisfaction and performance". Journal of Applied Psychology, Vol. 90 No. 5, pp. 945-955.

Anderson, E.W., Mittal, V. (2000). Strengthening the satisfaction-profit chain. J. Serv. Res. 3, 107-120.

Dadfar, H. \& Brege, S. (2012). "Differentiation by improving quality of services at the last touch point: the case of Tehran pharmacies”. International Journal of Quality and Service Sciences, Vol. 4 No. 4, pp. 345-363.

Ehigie, B. O. (2006). Correlates of customer loyalty to their bank: a case study in Nigeria. International Journal of Bank Marketing, 24(7), 494-508.

Ghozali, Imam. (2011). SEM metode alternatif dengan Partial Least Square (PLS). 3nd edition. Badan Penerbit Universitas Diponegoro

Hair, J. F., Hult, G. T. M., Ringle, C. \& Sarstedt, M. (2013). A Primer on Partial Least Squares Structural Equation Modeling (PLS-SE). Sage Publications, Inc.

Hallowell, R. (1995). "The relationships of customer satisfaction, customer loyalty, and profitability: an empirical study". International Journal of Service Industry Management, Vol. 7 No. 4, pp. 27-42.

Hutchinson, J., Lai, F. \& Wang, Y. (2009). "Understanding the relationship of quality, value, equity, satisfaction, and behavioural intentions among golf travellers". Tourism Management, Vol. 30, pp. 298-308.

Ittner, C.D. \& Larcker, D.F. (2003). "Coming up short on nonfinancial performance measurement". Harvard Business Review, Vol. 81 No. 11, pp. 88-95.

Kotler, P. (2000). Marketing Management, Prentice-HalI, Upper Saddle River, NJ.

Kotler, Phillip \& Kevin Lane Keller. (2007). Manajemen Pemasaran.Indeks.

Kursunluoglu, Emel. (2014). Shopping centre customer service: creating customer satisfaction and loyalty. Marketing Intelligence \& Planning Vol. 32 No. 4, 2014 pp. 528-548

Lam, R., \& Burton, S. (2006). SME banking loyalty (and disloyalty): a qualitative study in Hong Kong. International Journal of Bank Marketing, 24(1), 37-52.

Lee, J., Kim, H., Ko, Y.J. \& Sagas, M. (2011). "The influence of service quality on satisfaction and intention: a gender segmentation strategy”. Sport Management Review, Vol. 14, pp. 54-63.

Liang, X. \& Zhang, S. (2009). "Investigation of customer satisfaction in student food service". International Journal of Quality and Service Sciences, Vol. 1 No. 1, pp. 113-124.

Miles, P.C. (2013). "Competitive strategy: the link between service characteristics and customer satisfaction". International Journal of Quality and Service Sciences, Vol. 5 No. 4, pp. 395-414.

Okumuş A., Temizler Z. (2006). Süpermarket Müşterilerinin Mağzaya Olan Bağımlılık Derecelerine Göre Pazar Bölümlerinin Tanımlanması Ve Bölümler Arasındaki Farklılıkların Incelenmesi. Yönetim.17:54, 46-61.

Parasuraman, A., Zeithaml, V.A. \& Berry, L.L. (1998). "SERVQUAL: a multiple-item scale for measuring consumer perceptions of service quality". Journal of Retailing, Vol. 64 No. 1, pp. 12-40.

Senic, V. \& Marinkovic, V. (2014). "Examining the effect of different components of customer value on attitudinal loyalty and behavioral intentions". International Journal of Quality and Service Sciences, Vol. 6 Nos 2/3, pp. 134-142.

Sheth, J.N. \& Mittal, Banwari. (2004). Customer behavior: a manajerial perspective. Thomson Learning, Amerika.

Shin, Dong-Hee. (2014). Effect of the customer experience on satisfaction with smartphones: Assessing smart satisfaction index with partial least squares. Telecommunications Policy 39 (2015) 627-641

Suriyankietkaew, Suparak. (2016). Effects of sustainable leadership on customer satisfaction: evidence from Thailand. Asia-Pacific Journal of Business Administration Vol. 8 No. 3, 2016 pp. 245-259

Verhoef, P.C. (2003). Understanding the effect of customer relationship management efforts on customer retention and customer share development. Journal of Marketing 67 (4), 30-45.

Wulf, Schored \& Lacobucci. (2001). Marketing Research: Methodological Foundation, 9 th ed, BelmontCA:Thomson South Western. 